\title{
Control of $\mathrm{Hg}^{0}$ re-emission from gypsum slurries by means of additives in typical wet scrubber conditions
}

\author{
Raquel Ochoa-González*, Mercedes Díaz-Somoano and M. Rosa Martínez-Tarazona \\ Instituto Nacional del Carbón (INCAR), CSIC. C/ Francisco Pintado Fé, 26, 33011, \\ Oviedo, Spain
}

${ }^{*}$ Corresponding author

Phone: +34 985119090

Fax: +34 985297662

e-mail: $\underline{\text { rmtarazona@incar.csic.es }}$ 


\begin{abstract}
The effect of different additives on the re-emission of $\mathrm{Hg}^{0}$ in wet limestone-based flue gas desulphurisation (WFGD) conditions is assessed. Because re-emission of elemental mercury from natural limestone is dependent on the $\mathrm{pH}$ of the gypsum slurry, re-emission of elemental mercury was evaluated for different additives using gypsum slurry with a constant $\mathrm{pH}$ value of 7 . The additives investigated included oxidizing and reducing agents (Fenton reagents and sodium thiosulphate) and also chelating agents $(2,4,6$ trimercaptotriazine trisodium and sodium hydrosulfide). Fenton reagents were added to prevent the reduction of oxidized mercury species as $\mathrm{H}_{2} \mathrm{O}_{2}$ was the precursor used to convert sulfite ions into sulphate or to oxidize $\mathrm{Hg}^{0}$. Thiosulphate were added so that mercury could be retained in the gypsum at low concentrations as insoluble $\mathrm{HgS}$, while mercury is being stabilized in the liquid fraction at higher additive doses. The addition of 2,4,6 trimercaptotriazine trisodium (TMT) and NaHS in low doses prevented the reduction of oxidized mercury species as insoluble $\mathrm{HgS}$ and $\mathrm{Hg}_{3}$ (TMT) precipitate onto the gypsum slurry. TMT was found to be most effective additive for $\mathrm{Hg}^{2+}$ capture.
\end{abstract}

Keywords: wet FGD, additives, mercury capture

\title{
1. Introduction
}

Mercury and its compounds are highly toxic species which have a considerable impact on human health. Among the different mercury species, methylmercury is known to be the most toxic. What is more, there is clear evidence of the bioaccumulation and biomagnification of this neurotoxin in the aquatic food chain. Recent investigations have demonstrated that exposure to high levels of mercury may damage the brain, heart, kidneys, lungs and immune 
systems [1-2] and harmful effects have also been detected even at low concentrations [3]. Children are especially vulnerable to the effects of mercury since it interfers in the development of their reasoning and learning processes. For example prenatal methylmercury exposure has led to skin disorders and autism in Hong Kong children [4]. In terms of human exposure to mercury, fish consumption is the major exposure pathway, although inhalation may be another important source in areas with high concentrations of mercury in the air [5].

A large proportion of mercury is emitted to the environment by the burning of coal. This process is responsible for about one-third of anthropogenic mercury emissions [6]. Mercury may be present in flue gas as elemental mercury $\left(\mathrm{Hg}^{0}\right)$ or oxidized mercury $\left(\mathrm{Hg}^{2+}\right)$. It may also be retained in fly ash particles, in which case it is referred to as particle-bound mercury $\left(\mathrm{Hg}^{\mathrm{P}}\right)$. The proportion of the different mercury species varies throughout the system. As the temperature of the flue gases decreases mercury remains mainly as $\mathrm{Hg}^{2+}$ [7-8]. However, selective catalytic reduction (SCR) systems, which are used in some power plants to reduce $\mathrm{NO}_{\mathrm{x}}$ emissions, have been shown to cause an increase in the proportion of $\mathrm{Hg}^{2+}(\mathrm{g})$ in flue gases [9-10]. Whereas $\mathrm{Hg}^{\mathrm{P}}$ is retained in the electrostatic precipitators or bag filters, both $\mathrm{Hg}^{2+}$ and $\mathrm{Hg}^{0}$ species from the flue gas are emitted to the atmosphere in power plants without undergoing any post-combustion processes to reduce emissions. In some cases, wet flue gas desulphurization (WFGD) systems or scrubbers installed in coal fired power plants to control $\mathrm{SO}_{2}$ emissions have been used to decrease mercury emissions [11-12]. In such systems, $\mathrm{SO}_{2}$ reacts usually with the limestone slurry to produce insoluble gypsum.

$\mathrm{Hg}^{2+}$ can be efficiently captured in WFGD by taking advantage of its high solubility in water [13]. In fact, it has been calculated that the mercury removal efficiency of FGD systems ranges from 51 to $90 \%$ [11-12;14-15] and these values increase up to $89 \%$ if SCR systems are installed [16]. $\mathrm{Hg}^{2+}$ may follow one of three pathways in WFGD systems. It may react with 
other species to form $\mathrm{Hg}^{0}$ which is then re-emitted from the scrubber. It may be retained in the sludge and recirculated through the system or it may be captured in the grained fraction of solid by-products or gypsum. In the first case, oxidized mercury may be reduced by the aqueous $\mathrm{S}(\mathrm{IV})$ species (sulfite and/or bisulfite) resulting from the absorption of $\mathrm{SO}_{2}$ in the slurry [17]. In the second case, if the liquid fraction of the limestone slurry is recirculated, high concentrations of mercury may accumulate throughout the system giving rise to a new risk [18]. The last option appears to be the most suitable for desulphurization system which dispose of solid products at landfill sites if the spread of mercury is to be avoided. This involves using special additives for mercury capture as a mean of improving the efficiency of the WFGD system for the retention of mercury species in the solid fraction.

Another means of capture mercury involves the oxidation of $\mathrm{Hg}^{0}$ by chlorine and bromine species present in the flue gases [19-20], as well as the use of FGD oxidation additives, such us potassium permanganate and Fenton reagents. The oxidation rates of potassium permanganate are very high [21]. However, its application in desulphurization systems is not feasible due to its toxicity and ability to stain the gypsum. The Fenton process is based on the catalytic generation of hydroxyl radicals $\left(\mathrm{OOH}^{\bullet}\right)$ from $\mathrm{H}_{2} \mathrm{O}_{2}$ and metal ions such us copper or iron. Previous studies have shown that $\mathrm{Fe}^{3+}$ salts $\left(\mathrm{FeCl}_{3}\right.$ and $\left.\mathrm{Fe}_{2}\left(\mathrm{SO}_{4}\right)_{3}\right)$ have a greater capacity to oxidize $\mathrm{Hg}^{0}$ than the salts of other metal ions such as $\mathrm{Cu}^{2+}$ [22], but their effect on the re-emission of mercury has not yet received much attention. The reagents involved in this process are not only able to oxidize $\mathrm{Hg}^{0}$ but may also inhibit the reduction reactions of the oxidized mercury species.

Oxidation inhibition is neccesary in a dual alkali FGD system to improve reliability. Sodium thiosulfate has been demonstrated to be an effective oxidation inhibitor of sulphite in lime or 
limestone slurry or in highly diluted sulfite solutions [23]. However, its effect on mercury removal has not been studied until now.

The most recent research focussed on the chelating capacity of $\mathrm{Hg}^{2+}$ sequesters such as $2,4,6$ trimercaptotriazine trisodium (TMT) and sulphides. The results indicate that TMT has a lower chelating capacity than $\mathrm{Na}_{2} \mathrm{~S}[24]$ and that the dose of TMT should be kept to the minimum in order to limit emissions of mercury since doses that are too high could lead to the reduction of mercury instead of its precipitation [25]. However, these results have not been demonstrated in wet scrubber conditions with limestone slurry as the sorbent.

The objective of the present work was to evaluate the effectiveness of different additives in reducing mercury re-emission in gypsum slurries derived from natural limestone and to study the partitioning of this element in the solid and liquid byproducts. The effect of using ironbased Fenton-type additives and sodium thiosulphate to improve mercury retention in FGD systems was also assessed. The mercury capture efficiency of sodium hydrosulphide was compared with that of TMT in wet scrubber conditions.

\section{Experimental}

To investigate the reactions involved in $\mathrm{Hg}^{0}$ re-emission in wet flue gas desulphurization facilities, a FGD lab-scale device was set up [26]. A commercial evaporator (HovaCAL, IAS $\mathrm{GmbH}$ ) was used to generate mercury species from an aqueous mercury solution, which was stabilized in a hydrochloric acid medium and allowed to evaporate continuously at $200^{\circ} \mathrm{C}$. The mercury in gas phase was conducted to a $\mathrm{N}_{2}$ atmosphere. This resulted in a flue gas containing $\mathrm{N}_{2}$ and $50 \mu \mathrm{g} / \mathrm{m}^{3}$ of $\mathrm{Hg}^{2+}$ which was maintained at $3 \mathrm{~L} / \mathrm{min}$ by means of a mass flow controller. 
The reactor consisted of a $500 \mathrm{ml}$ flask made of glass with three connections: an inlet and an outlet for the flue gas and an additional connection for the $\mathrm{pH}$ electrode and a titrator. The reactor was stirred to favour the mixing of the mercury with the sorbent and the reactants, and kept at constant temperature $\left(40^{\circ} \mathrm{C}\right)$ during the tests since mercury reduction is sensitive to the operating temperature. The $\mathrm{pH}$ was kept constant at 7 to favour the formation of sulphite ions in the slurry. The $\mathrm{pH}$ was adjusted continuously by adding sulphuric acid $0.1 \mathrm{~N}$ with a continuous titrator. For each test, a slurry containing $1 \%$ of natural limestone and $0.1 \mathrm{~mol} / \mathrm{L}$ of sulphuric acid was placed in the reactor. The gas before and after the reactor was conducted through PFA pipes which were heated at $120^{\circ} \mathrm{C}$ by means of a temperature-controlled heating tape to prevent the condensation of moisture and the adsorption of mercury on its surface.

A continuous mercury emission monitor (VM 3000, Mercury Instruments) was used to measure the elemental mercury generated through the reduction of oxidised mercury species during the experiments. The mercury content of the gypsum and aqueous samples generated in the lab-scale tests was determined by means of an Advance Mercury Analyser (AMA-254). The gypsum samples were dried for $48 \mathrm{~h}$ at $40^{\circ} \mathrm{C}$ prior to analysis to avoid decomposition of the samples and loss of mercury.

The stability of the mercury in the gypsum samples obtained from the laboratory-scale tests was evaluated in water in accordance with the UNE-EN 12457-2 norm. Leaching tests were performed in duplicate using a 1:40 solid:liquid ratio. The samples were mixed with water for 24 hours after which the gypsum slurry was filtered. The mercury dissolved in the liquid fraction was analyzed using the AMA.

For the analysis of $\mathrm{Fe}$ in the gypsum, the samples were previously digested with $\mathrm{HNO}_{3}: \mathrm{HCl}$ at a ratio of 3:1 in a microwave oven. The analyses were carried out in a ICP-MS 7700x Agilent device equipped with a He collision cell to eliminate matrix interferences. 


\section{Results and discussion}

\section{Optimization of the $\mathrm{pH}$ for the re-emission of $\mathrm{Hg}^{\mathbf{0}}$}

The effect of the $\mathrm{pH}$ on mercury re-emission was evaluated. Fig. 1 shows that the re-emission of $\mathrm{Hg}^{0}$ from the reactor containing limestone and gypsum slurries is dependent on $\mathrm{pH}$ values. These were adjusted by using diluted sulfuric acid. It can be seen that the mercury concentration detected corresponds to the amount of $\mathrm{Hg}^{0}$ re-emitted and increases at $\mathrm{pH}$ values higher than 5 . More than $50 \%$ of the $\mathrm{Hg}^{0}$ was produced when $\mathrm{pH}$ was kept constant at 6 and at $\mathrm{pH}=7$ nearly $100 \%$ reduction was achieved. These results confirm that mercury capture in FGD systems depends on the $\mathrm{pH}$ of the slurry as the formation of sulfite ions is a function of the $\mathrm{pH}($ Eq.1).

$$
\mathrm{Hg}^{2+}+\mathrm{SO}_{3}{ }^{2-}+\mathrm{H}_{2} \mathrm{O} \leftrightarrow \mathrm{Hg}^{0}+\mathrm{SO}_{4}{ }^{2-}+2 \mathrm{H}^{+}
$$

For $\mathrm{pH}$ values between 4 and 5 more than $90 \%$ of the mercury captured was retained in the liquid fraction of the slurry, as $\mathrm{HgCl}_{2}$ is the main mercury species in the flue gas. A pH value of 7 was selected to carry out the retention experiments since the highest degree of $\mathrm{Hg}^{2+}$ reduction was achieved in these conditions.

\section{Fenton additives}

When using a Fenton reactive, most of the mercury will be retained in the slurry in a $\mathrm{pH}$ range of 3-4 in which the oxidant radicals are formed. However, at the high $\mathrm{pH}$ values typical of FGD plants, the formation of such radicals is more difficult. In these more unfavorable conditions, mercury behavior was compared introducing $\mathrm{Fe}^{3+}$ additives $\left(\mathrm{FeCl}_{3}\right.$ and $\left.\mathrm{Fe}_{2}\left(\mathrm{SO}_{4}\right)_{3}\right)$ into the slurry.

The re-emission of $\mathrm{Hg}^{0}$ was evaluated employing different concentrations of $\mathrm{Fe}_{2}\left(\mathrm{SO}_{4}\right)_{3}$ in the absence and presence of $\mathrm{H}_{2} \mathrm{O}_{2}$ (Fig. 2a). It was found that $\mathrm{Fe}_{2}\left(\mathrm{SO}_{4}\right)_{3}$ does not affect the 
reduction of mercury. However, when $200 \mathrm{mg} / \mathrm{mL}$ of $\mathrm{H}_{2} \mathrm{O}_{2}$ was added, the mercury in the slurry stabilized. It was also observed that the partitioning of mercury among the products is modified as a function of the concentration of $\mathrm{Fe}_{2}\left(\mathrm{SO}_{4}\right)_{3}$. Although the re-emission of $\mathrm{Hg}^{0}$ is similar for the different concentrations of $\mathrm{Fe}_{2}\left(\mathrm{SO}_{4}\right)_{3}$ tested (Fig. 2a), the presence of high concentrations of $\mathrm{Fe}_{2}\left(\mathrm{SO}_{4}\right)_{3}$ in the slurry increases the mercury retained in the solid fraction (Fig. 2c). This may be due not only to the adsorption of $\mathrm{Hg}^{2+}$ onto the gypsum particles but also to the formation of $\mathrm{HgSO}_{4}$, which decomposes into $\mathrm{HgO}(\mathrm{s})$ at $\mathrm{pH}$ values of around 7 . Moreover the addition of $\mathrm{Fe}^{3+}$ may favor the co-precipitation of mercury with $\mathrm{Fe}(\mathrm{OH})_{3}$ particles.

With the $\mathrm{FeCl}_{3}$ additive the results obtained by varying the concentration of $\mathrm{Fe}^{3+}$ between 25 and $200 \mathrm{mg} / \mathrm{mL}$ (Fig. 2b) also show that the combination of $\mathrm{FeCl}_{3}$ and $\mathrm{H}_{2} \mathrm{O}_{2}$ prevents the reemission of $\mathrm{Hg}^{0}$. As in the case of $\mathrm{Fe}_{2}\left(\mathrm{SO}_{4}\right)_{3}$, this is a consequence of the stabilization of mercury in the solution in the presence of $\mathrm{H}_{2} \mathrm{O}_{2}$. These results also suggest that under the experimental conditions of this study chloride ions resulting from the dissolution of $\mathrm{FeCl}_{3}$ are unable to enhance mercury capture in the gypsum slurry because the reduction of $\mathrm{Hg}^{2+}$ by sulfite ions is thermodynamically more favored. The mercury partitioning in the byproducts indicates that an increase in mercury retention in the solid fraction occurs at higher concentrations of $\mathrm{FeCl}_{3}$ (Fig. 2d), although the amount of mercury retained in the solid is lower than in the case of $\mathrm{Fe}_{2}\left(\mathrm{SO}_{4}\right)_{3}$ (Fig. 2c). This suggests that sulfate ions may be contributing to the formation of a small amount of mercury sulfate which then precipitates with the gypsum particles or decomposes into $\mathrm{HgO}(\mathrm{s})$. This would reinforce the main mechanism proposed above whereby mercury is adsorbed onto the particles of gypsum or $\mathrm{Fe}(\mathrm{OH})_{3}$. The iron content in the gypsum samples varies between $0.26\left(25 \mathrm{mg} / \mathrm{L} \mathrm{Fe}^{3+}\right)$ and $1.5 \%\left(200 \mathrm{mg} / \mathrm{L} \mathrm{Fe}^{3+}\right)$, indicating there may be a correlation between the concentration of 
$\mathrm{Fe}^{3+}$ and $\mathrm{Hg}$ capture. It is also possible that the high concentration of mercury that accumulates in the liquid fraction with the addition of $\mathrm{FeCl}_{3}$ may be due to the stabilization of $\mathrm{Hg}^{2+}$ as $\mathrm{HgCl}_{2}$ in solution.

When the effect of different concentrations of $\mathrm{H}_{2} \mathrm{O}_{2}$ in the slurry was evaluated in the absence of iron salts (Fig. 3a) it was found that for low concentrations of $\mathrm{H}_{2} \mathrm{O}_{2}(1 \mathrm{mg} / \mathrm{mL})$, mercury stabilizes in the gypsum slurry. However, if the partitioning between the solid and liquid fractions is evaluated (Fig. 3b), there is a significant reduction in the amount of mercury captured in the solid compared to that retained using iron salts. Only $2 \%$ of the ercury was retained in the absence of $\mathrm{H}_{2} \mathrm{O}_{2}$ due to the high amount of $\mathrm{Hg}^{2+}$ converted to $\mathrm{Hg}^{0}$ in the gypsum slurry, while no mercury was found in the liquid fraction. In contrast, when $\mathrm{H}_{2} \mathrm{O}_{2}$ is added in concentrations in the range of 1 to $300 \mathrm{mg} / \mathrm{mL}$ (Fig. 3b), the percentage of mercury retained in the solid increases to $20 \%$ for different concentrations of $\mathrm{H}_{2} \mathrm{O}_{2}$, even though most of the mercury is retained in the liquid fraction of the slurry as $\mathrm{HgCl}_{2}$.

The possible leaching of mercury from the gypsum samples was also evaluated by carrying out leaching tests in water. As can be seen from Table 1, 3\% of soluble mercury was detected in the leaching experiments using the gypsum obtained in the presence of $\mathrm{FeCl}_{3}$. As the mercury concentrations in the gypsum samples obtained by adding $\mathrm{Fe}_{2}\left(\mathrm{SO}_{4}\right)_{3}$ and $\mathrm{FeCl}_{3}$ are similar, it is likely that when $\mathrm{FeCl}_{3}$ is used mercury is absorbed as $\mathrm{HgCl}_{2}$, which then dissolves in water. No leaching of mercury occurred in the gypsum samples obtained when only $\mathrm{H}_{2} \mathrm{O}_{2}$ was used. However, this may be due to the low concentration of mercury in the sample or to the presence of other mercury species of lower solubility such as $\mathrm{HgSO}_{4}$ and $\mathrm{HgO}$.

The results obtained in Figures 2 and 3 indicate that the addition of $\mathrm{H}_{2} \mathrm{O}_{2}$, whether in the presence or absence of $\mathrm{Fe}^{3+}$ salts, prevents $\mathrm{Hg}^{0}$ re-emission. It appears that $\mathrm{H}_{2} \mathrm{O}_{2}$ not only 
oxidizes the $\mathrm{Hg}^{0}$ formed in the scrubber, but it also reduces the generation of sulfite ions. This shows that the stability of mercury in the reactor is essentially due to the oxidizing effect of $\mathrm{H}_{2} \mathrm{O}_{2}$. However, as the flue gas from coal combustion contains high concentrations of $\mathrm{SO}_{2}$, $\mathrm{H}_{2} \mathrm{O}_{2}$ could be consumed by the sulphur species in the scrubber system.

\section{Thiosulphate}

The thiosulfate ion is a reductor species which prevents the oxidation of sulfur species present in the slurry and, as a consequence, it alters the sulfite/sulfate ratio. However, its reducing effect is not strong enough to convert oxidised mercury species into elemental mercury. This additive has several advantages over the other additives used, including its non-toxicity and its low cost. In the experimental conditions of this work, it was observed that the re-emission of $\mathrm{Hg}^{0}(\mathrm{~g})$ decreases as the sodium thiosulfate concentration increases (Fig. 4a). However, for concentrations of thiosulfate between 10 and $20 \mathrm{mM}$, the retention of oxidized mercury does not reach $100 \%$. Mercury capture in the gypsum increases when the amount of thiosulfate added is in the concentration range of 1 and $5 \mathrm{mM}$ (Fig. $4 \mathrm{~b}$ ) due to the formation of $\mathrm{HgS}$, as shown by Eq.2:

$$
\mathrm{HgCl}_{2}+\mathrm{S}_{2} \mathrm{O}_{3}{ }^{2-}+\mathrm{H}_{2} \mathrm{O} \rightarrow \mathrm{HgS}+\mathrm{SO}_{4}{ }^{2-}+2 \mathrm{Cl}^{-}+2 \mathrm{H}^{+}
$$

For higher concentrations of thiosulfate ions $(10$ and $20 \mathrm{mM})$, the mercury is mainly retained in the liquid fraction because it forms complexes such as $\mathrm{HgS}_{2} \mathrm{O}_{3}$ and $\mathrm{Hg}\left(\mathrm{S}_{2} \mathrm{O}_{3}\right)_{2}{ }^{2-}$ which are stable in solution (Blythe et al., 2008). In short, the partitioning of mercury into liquid and solid fractions depends on the concentration of thiosulphate.

Leaching tests carried out with gypsum generated in the presence of $\mathrm{Na}_{2} \mathrm{~S}_{2} \mathrm{O}_{3}$ indicate that, despite the high concentrations of mercury in the gypsum, the mercury species are insoluble in water, which is agreement with the reaction mechanism of Eq 2. 


\section{Hydrosulphide}

Fig. 5a shows the $\operatorname{Hg}^{0}(\mathrm{~g})$ curves when the gypsum slurry contains different amounts of sodium hydrosulphide. $\mathrm{Hg}^{0}$ emissions decrease as the sodium hydrosulphide concentration increases. However, a concentration of at least $1 \mathrm{mmol} / \mathrm{L}$ of sodium hydrosulphide is required to produce any significant reduction in mercury emission. Fig. $5 \mathrm{~b}$ shows the distribution of mercury in the gas, liquid and solid byproducts for different concentrations of sodium hydrosulphide. It can be seen that mercury retention by the gypsum is enhanced by high concentrations of sodium hydrosulphide. With this additive, mercury forms $\mathrm{HgS}$ in the slurry in accordance with Eq.3. $\mathrm{HgS}$ is then adsorbed onto the gypsum particles.

$$
\mathrm{NaHS}+\mathrm{Hg}^{2+} \rightarrow \mathrm{HgS}+\mathrm{H}^{+}+\mathrm{Na}^{+}
$$

Leaching tests using the gypsum produced in the presence of NaHS show that the mercury species present in the solid fraction are insoluble in water, which indicates the formation of $\mathrm{HgS}$.

\section{TMT}

Fig. 6a represents the emission of $\mathrm{Hg}^{0}(\mathrm{~g})$ for different concentrations of TMT. No re-emission of $\mathrm{Hg}^{0}$ occurs for concentrations of additive higher than $8.010^{-5} \mathrm{mmol} / \mathrm{L}$. The amount of $\mathrm{Hg}^{0}$ generated was significant only for $4.010^{-5} \mathrm{mmol} / \mathrm{L}$ of TMT. Fig. $6 \mathrm{~b}$ shows the proportion of mercury retained in the gypsum and flue gas. All of the mercury precipitates as $\mathrm{Hg}_{3} \mathrm{TMT}$ with the gypsum as no mercury was detected in the liquid fraction. The leaching tests carried out with the gypsum generated in the presence of TMT demonstrate that the mercury species formed are insoluble in water. A comparison of the additives NaHS and TMT based on the 
stoichiometry of Eq.3 and 4 ( 1 and 1.5 respectively) shows that TMT has a higher mercury capture capacity than NaHS.

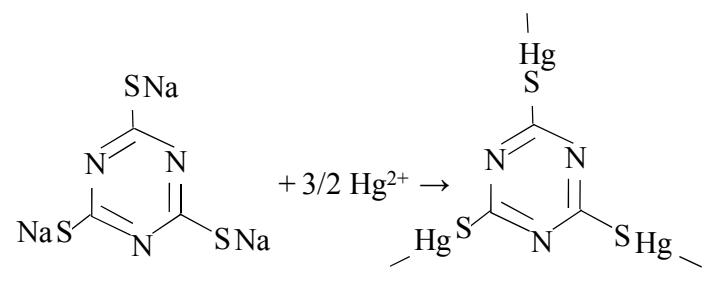

\section{Conclusions}

The effect that different additives have on elemental mercury re-emission has been studied under conditions in which the $\mathrm{pH}$ of the gypsum slurry is kept constant. The simulation of FGD wet scrubber slurries, where most of the oxidized mercury is reduced by sulfite ions or metals derived from limestone, demonstrated the ability of these additives to stabilize mercury in the solid and liquid fractions. Fenton reagents were added to prevent the reduction of oxidized mercury species. The oxygenated water in the Fenton reagent converts the sulfite ions into sulphate. $\mathrm{OOH}^{\bullet}$ radicals were observed to have no effect on $\mathrm{Hg}^{0}$ oxidation at the $\mathrm{pH}$ of the experiments. When sodium thiosulphate is added mercury is retained in the gypsum at low concentrations while with higher doses of additive mercury is stabilised in the liquid fraction. The addition of TMT and NaHS prevents the reduction of oxidized mercury species into insoluble $\mathrm{HgS}$ and $\mathrm{Hg}_{3}(\mathrm{TMT})$. TMT is more effective for $\mathrm{Hg}^{2+}$ capture and has the advantage that only a small proportion of additive is necessary to stabilize the mercury in WFGD systems.

\section{Acknowledgements}


This work was financed by the projects CTM2011-22921 and PI Programme (CSIC) (Ref. PI200780I008). R.O.G. thanks FICYT (Regional research programme) for funding her PhD work through a fellowship. 
Table 1. Mercury concentrations in gypsum samples $(\mu \mathrm{g} / \mathrm{g})$ and leaching mercury.

\begin{tabular}{|c|c|c|}
\hline Test & Hg concentration $(\mu \mathrm{g} / \mathrm{g})$ & Leaching of $\mathrm{Hg}(\%)$ \\
\hline Blank (gypsum) & 0.34 & n.d. \\
\hline $50 \mathrm{mg} / \mathrm{mL} \mathrm{H}_{2} \mathrm{O}_{2}$ & 1.80 & n.d. \\
\hline $50 \mathrm{mg} / \mathrm{mL} \mathrm{FeCl}{ }_{3}+200 \mathrm{mg} / \mathrm{mL} \mathrm{H}_{2} \mathrm{O}_{2}$ & 6.37 & 3 \\
\hline $50 \mathrm{mg} / \mathrm{mL} \mathrm{Fe}{ }_{2}\left(\mathrm{SO}_{4}\right)_{3}+200 \mathrm{mg} / \mathrm{mL} \mathrm{H}_{2} \mathrm{O}_{2}$ & 5.20 & n.d. \\
\hline $5 \mathrm{mM} \mathrm{NaHS}$ & 14.0 & n.d. \\
\hline $5 \mathrm{mM} \mathrm{Na}_{2} \mathrm{~S}_{2} \mathrm{O}_{3}$ & 12.3 & n.d. \\
\hline $210^{-4} \mathrm{mM}$ TMT & 19.5 & n.d. \\
\hline
\end{tabular}




\section{Figure captions}

Figure 1. Influence of the $\mathrm{pH}$ of the gypsum slurry on $\mathrm{Hg}^{0}$ re-emission.

Figure 2. Effect of $\mathrm{Fe}_{2}\left(\mathrm{SO}_{4}\right)_{3}$ on mercury retention $\left(\left[\mathrm{H}_{2} \mathrm{O}_{2}\right]=200 \mathrm{mg} / \mathrm{mL}\right)$ (a). Relationship between the proportion of mercury retained in the solid and liquid fraction of the slurry and the concentration of $\mathrm{Fe}_{2}\left(\mathrm{SO}_{4}\right)_{3}\left(\left[\mathrm{H}_{2} \mathrm{O}_{2}\right]=200 \mathrm{mg} / \mathrm{mL}\right)$ (b). Effect of $\mathrm{FeCl}_{3}$ concentration on the retention of mercury $\left(\left[\mathrm{H}_{2} \mathrm{O}_{2}\right]=200 \mathrm{mg} / \mathrm{mL}\right)(\mathrm{c})$. Relationship between the proportion of mercury retained in the solid and liquid fraction for different concentrations of $\mathrm{FeCl}_{3}\left(\left[\mathrm{H}_{2} \mathrm{O}_{2}\right]\right.$ $=200 \mathrm{mg} / \mathrm{mL})(\mathrm{d})$.

Figure 3. Effect of $\mathrm{H}_{2} \mathrm{O}_{2}$ concentration on mercury retention (a) and relationship between the proportion of mercury retained in the solid and liquid fractions and the concentration of $\mathrm{H}_{2} \mathrm{O}_{2}$ (b).

Figure 4. Elemental mercury emission when different quantities of $\mathrm{Na}_{2} \mathrm{~S}_{2} \mathrm{O}_{3}$ are added to the gypsum slurry (a) and the distribution of mercury in the gas and desulfurization products for different concentrations of sodium thiosulfate (b).

Figure 5. Elemental mercury emissions for different concentrations of NaHS (a) and the distribution of mercury in the gas and the solid fractions as a function of the concentration of sodium hydrosulphide (b).

Figure 6. Effect of the concentration of TMT on the retention of mercury (a) and relationship between mercury distribution and the concentration of TMT (b). 


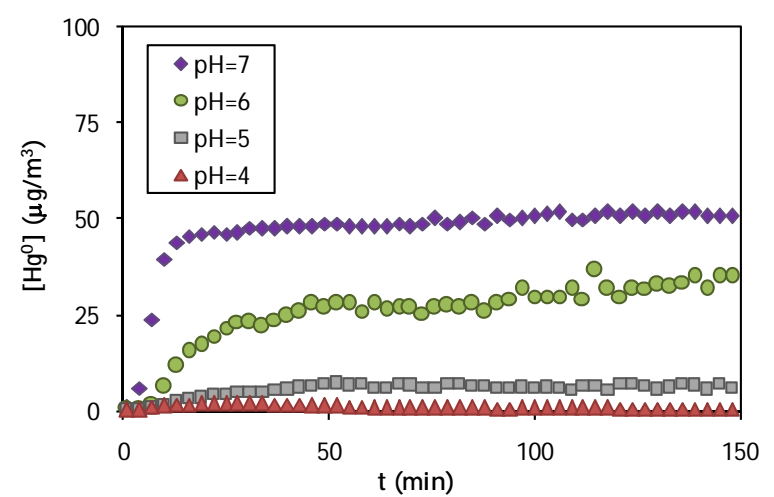

Figure 1. Influence of the $\mathrm{pH}$ of gypsum slurry on $\mathrm{Hg}^{0}$ re-emission. 


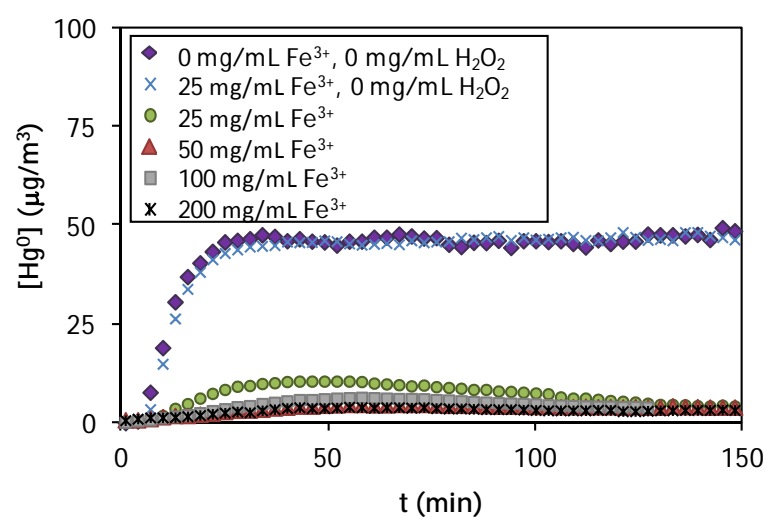

(a)

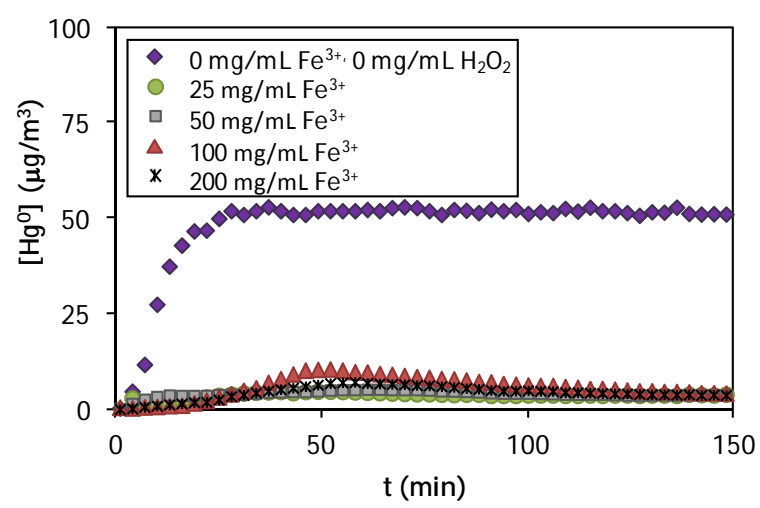

(b)

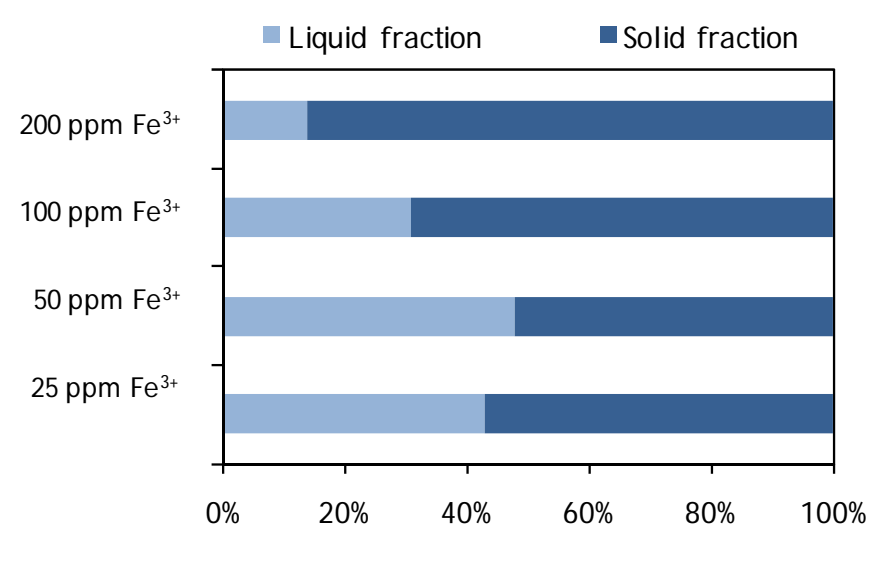

(c)

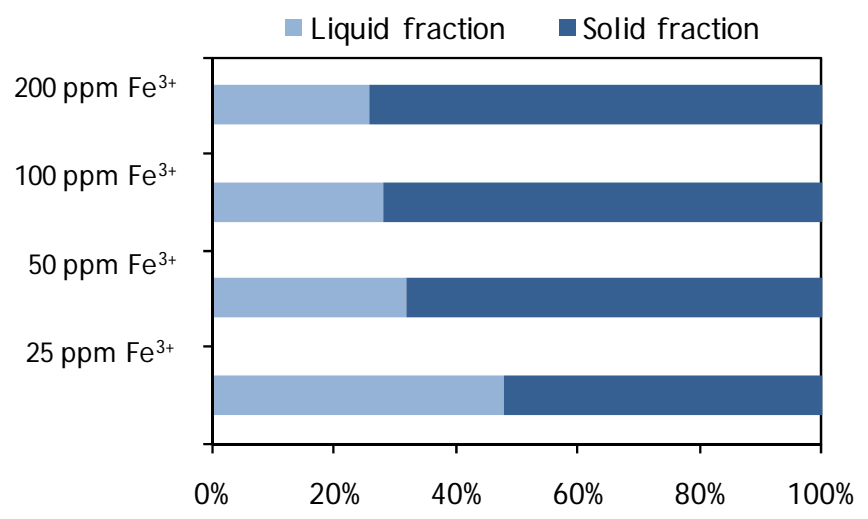

(d)

Figure 2. Effect of $\mathrm{Fe}_{2}\left(\mathrm{SO}_{4}\right)_{3}$ and $\mathrm{FeCl}_{3}$ on mercury retention $\left(\left[\mathrm{H}_{2} \mathrm{O}_{2}\right]=200 \mathrm{mg} / \mathrm{mL}\right)((\mathrm{a})$ and (b), respectively) and relationship between the proportion of mercury retained in the solid and liquid fraction of the slurry and the concentration of $\mathrm{Fe}_{2}\left(\mathrm{SO}_{4}\right)_{3}$ and $\mathrm{FeCl}_{3}\left(\left[\mathrm{H}_{2} \mathrm{O}_{2}\right]=200\right.$ $\mathrm{mg} / \mathrm{mL})((\mathrm{c})$ and (d), respectively). 


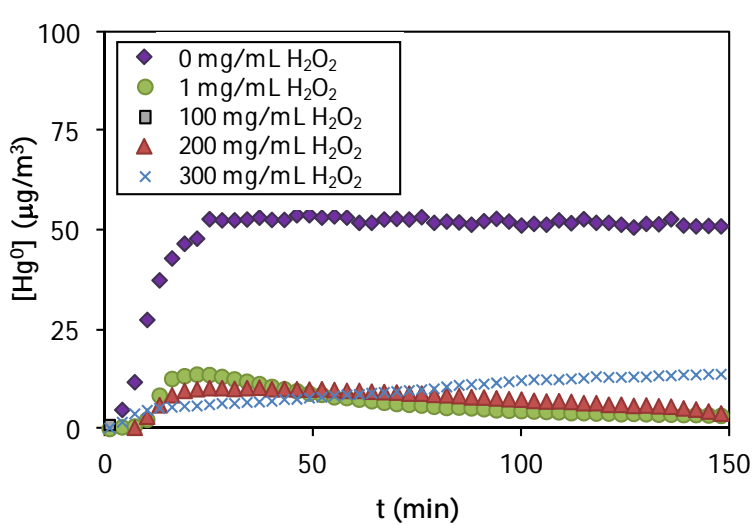

(a)

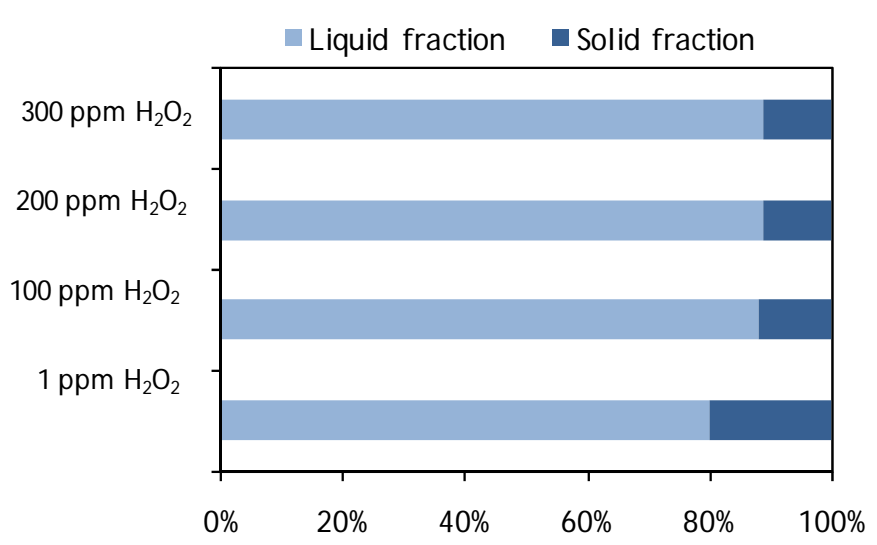

(b)

Figure 3. Effect of the $\mathrm{H}_{2} \mathrm{O}_{2}$ concentration on mercury retention (a) and the relationship between the proportion of mercury retained in the solid and liquid fractions and the concentration of $\mathrm{H}_{2} \mathrm{O}_{2}(b)$. 


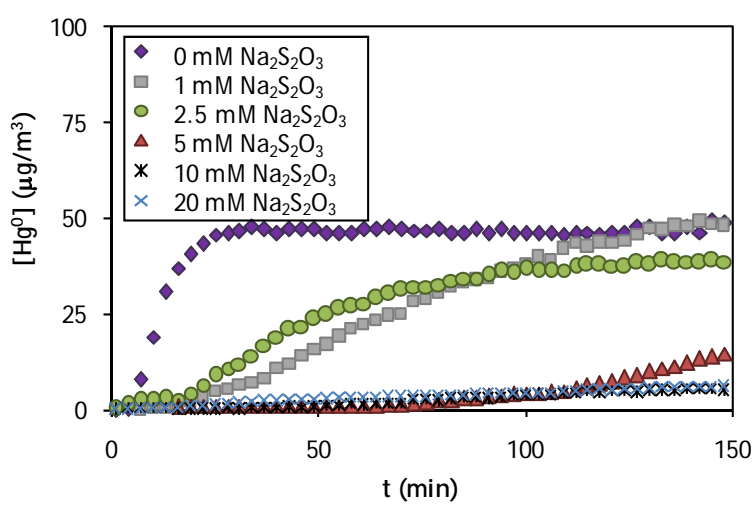

(a)

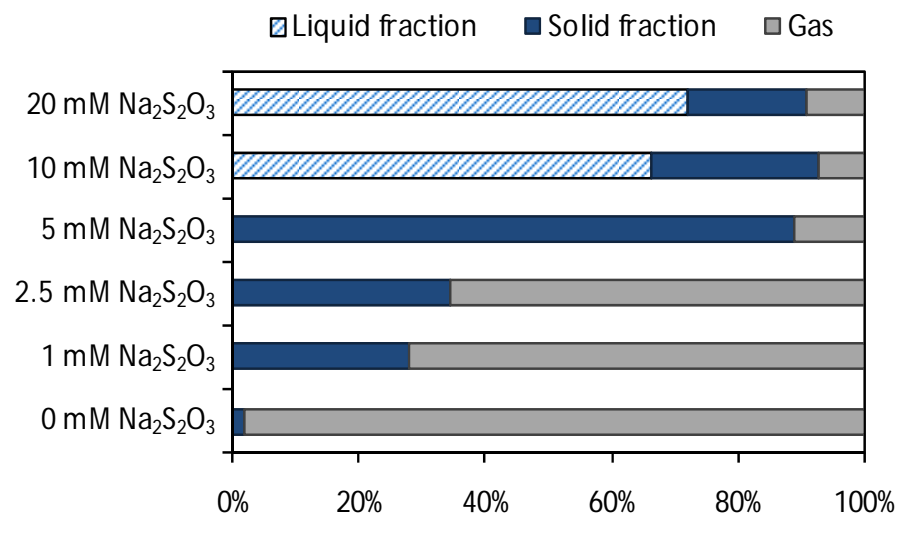

(b)

Figure 4. Elemental mercury emission when different quantities of $\mathrm{Na}_{2} \mathrm{~S}_{2} \mathrm{O}_{3}$ are added to the gypsum slurry (a) and distribution of mercury in the gas and desulfurization products for different concentrations of sodium thiosulfate (b). 


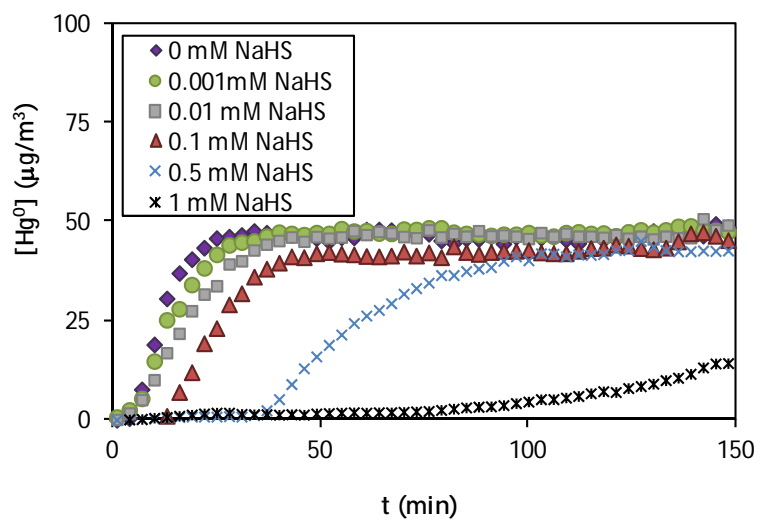

(a)

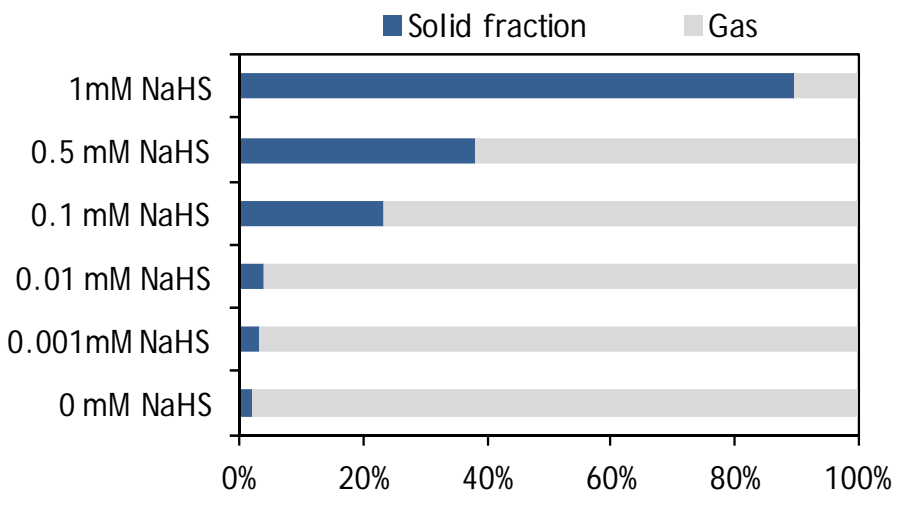

(b)

Figure 5. Elemental mercury emission for different concentrations of NaHS (a) and the distribution of mercury in the gas and solid fractions as a function of the concentration of sodium hydrosulphide (b). 


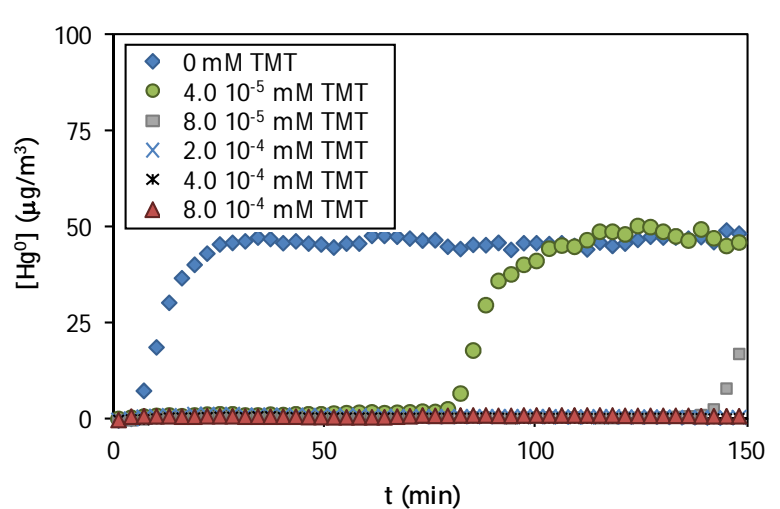

(a)

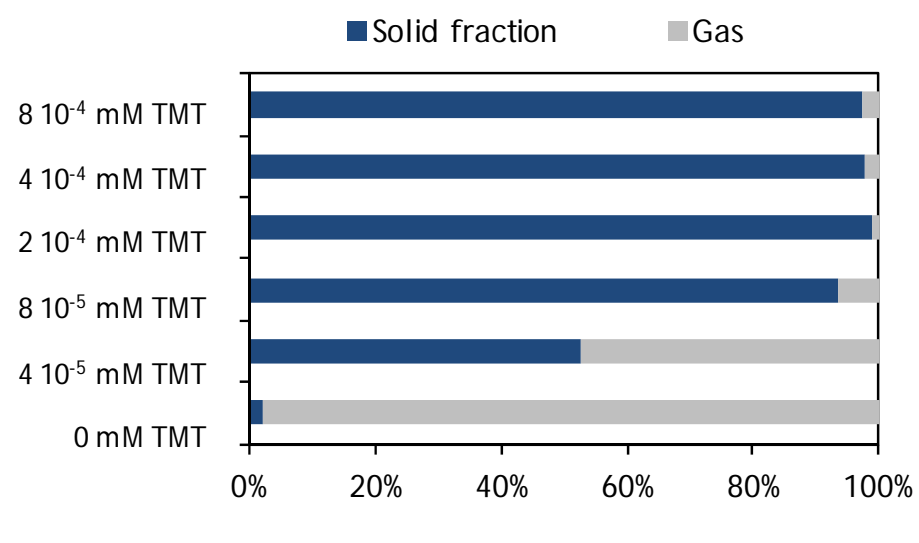

(b)

Figure 6. Effect of the concentration of TMT on the retention of mercury (a) and the relationship between mercury distribution and the concentration of TMT (b). 


\section{References}

[1] EPA: http://www.epa.gov/hg/effects.htm

[2] Allen-Counter S, H.-Buchanan L. Mercury exposure in children: a review. Toxicology and Applied Pharmacology 2004; 198:209-230.

[3] Boening WD. Ecological effects, transport, and fate of mercury: a general review. Chemosphere 2000; 40:1335-1351.

[4] Zhang L, Wong MH. Environmental mercury contamination in China: Sources and impacts. Environment International 2007; 33:108-121.

[5] $\mathrm{Fu} \mathrm{X}$, et al. Temporal and spatial distributions of total gaseous mercury concentrations in ambient air in a mountainous area in southwestern China: Implications for industrial and domestic mercury emissions in remote areas in China. Science of total Environment 2009; 407:2306-2314.

[6] Jensen RR, Karki S, Salehfar H. Artificial neural network-based estimation of mercury speciation in combustion flue gases. Fuel Process Technol 2004; 85:451-462.

[7] Yan R, Liang DT, Tay JH. Control of mercury vapor emissions from combustion flue gas. Environ. Sci. Pollut. Res. 2003; 10:399-407.

[8] Ochoa-González R et al. Differential partitioning and speciation of $\mathrm{Hg}$ in wet FGD facilities of two Spanish PCC power plants. Chemosphere 2011; 85:565-570.

[9] Lee CW, Srivastava RK. Investigation of Selective Catalytic Reduction Impact on Mercury Speciation under Simulated NOx Emission Control Conditions. Air \& Waste Manage. Assoc. 2004; 54:1560-1566.

[10] Richardson C, Machalek T, Miller S, Dene C, Chang R. Effect of NOx control process on mercury speciation in utility flue gas. Journal of the Air and Waste Management Association 2002; 52:941-947. 
[11] Chin-Min C et al. Partitioning of Mercury, Arsenic, Selenium, Boron, and Chloride in a Full-Scale Coal Combustion Process Equipped with Selective Catalytic Reduction, Electrostatic Precipitation, and Flue Gas Desulfurization Systems. Energy Fuels 2009; 23:4805-4816.

[12] Meij R, te Winkel H. The emissions of heavy metals and persistent organic pollutants from modern coal-fired power stations. Atmospheric Environment 2007; 41:9262-9272.

[13] Kilgroe JD, Sedman CB, Srivastava RK, Ryan JV, Lee CW, Thorneloe SA. Control of mercury emissions from coal-fired electric utility boilers. 2002; EPA Report 600/R01/109.

[14] Smith IM. Management of FGD Residues. IEA Clen Coal Centre 2006.

[15] Pavlish JH et al. Status review of mercury control options for coal-fired power plants. Fuel Processing Technology 2003; 82:89-165.

[16] Withum JA, Tseng SC, Locke JE. Mercury Emissions from Coal-Fired Facilities with SCR-FGD Systems. 2006, DOE/NETL’s Mercury Control Technology Conference.

[17] Chang JCS, Ghorishi S.B. Simulation and evaluation of elemental mercury concentration increase in flue gas across a wet scrubber. Environ Sci Technol 2003; 37:5763-5766.

[18] Córdoba P et al. Enrichment of inorganic trace pollutants in re-circulated water streams from a wet limestone flue gas desulphurisation system in two coal power plants. Fuel Processing Technology 2011; 92:1764-1775.

[19] Strivastava R. Control of Mercury Emissions from Coal Fired Electric Utility Boilers: An Update. 2010. http://www.epa.gov/nrmrl/pubs/600r10006/600r10006.pdf

[20] Niksa S, Naik CV, Berry MS, Monroe L. Interpreting enhanced Hg oxidation with Br addition at Plant Miller. Fuel Processing Technology 2009; 90:1372-1377. 
[21] Hutson ND, Krzyzynska R and Srivastava RK. Simultaneous Removal of SO2, NOx and $\mathrm{Hg}$ from Coal Combustion Flue Gas using a NaClO2-Enhaced scrubber. Ind. Eng. Chem. Res. 2008; 47:5825-5831.

[22] Lu D, Anthony E J., Tan Y, Dureau R, Ko V, Douglas MA. Mercury removal from coal combustion by Fenton reactions- Part A: Bench scale tests. Fuel 2007; 86:2789-2797.

[23] Jim-Song M. Zhong-Biao W, Chang-Jie C, Bao-Hong G, Wei-Ron Z. Oxidation inhibition of sulfite in dual alkali flue gas desulfurization system. Journal of Environmental Sciences 2007; 19:226-231.

[24] Tang T, Xu J, Lu R, Wo J, Xu X. Enhanced Hg2+ removal and Hg0 re-emission control from wet fuel gas desulfurization liquors with additives. Fuel 2010; 89: 3613-3617.

[25] Blythe GM, Currie J, DeBerry DW, Miller C. Bench scale kinetics study of mercury reactions in FGD liquors. 2008; Cooperative Agreement No: DE-FC26-04NT42314.

[26] Ochoa González R, Díaz-Somoano M, López-Antón MA, Martínez-Tarazona MR. Effect of adding aluminium salts to wet FGD systems upon the stabilization of mercury. Fuel 2012; article in press. 